\title{
Stem cells: characterization and measurement
}

\author{
ROB E. PLOEMACHER PhD
}

Senior Lecturer/Associate Professor

Department of Haematology, Erasmus University, PO Box 1738, 3000 DR, Rotterdam, The Netherlands

\begin{abstract}
The process of blood formation is sustained throughout an individual's life by a small population of haemopoietic stem cells (HSCs). The HSC compartment represents a hierarchy of HSC subsets with decreasing proliferative ability. This heterogeneity is reflected in the varying time periods that HSCs may contribute to the initiation and maintenance of donor-type haemopoietic multilineage chimerism in vivo. The phenotype of HSC is incompletely defined rendering morphological or flow cytometric quantitation unreliable. Functional HSC assays, both in vitro (CAFC, LTC-IC) and in vivo (repopulation of NOD/SCID mice) may be superior to phenotypic analysis; however, such assays have not been truly validated in a human transplant setting.

The quiescence and proliferation of HSCs is highly regulated by the stroma in haemopoietic organs. Many of the cytokines that have been cloned in recent years are actually elaborated and presented by the haemopoietic organ stroma and are supposed to serve as local regulators in order to gain specificity and avoid pleitropic and thus undesired side effects. Most probably, additional stroma-derived factors will be characterized as suggested by the observation that HSCs produce more progeny in stroma-contact than in its absence or in stroma-conditioned medium, irrespectively of the exogenous cytokines included.

Stem cells are considered to possess the ability to self-renew and are therefore attractive vehicles for gene therapy. The same assumed characteristic fuels attempts to amplify their numbers ex vivo, and is expected to enable more rapid haemopoietic recovery of conditioned recipients as well as enlarge HSC grafts of insufficient size before actual transplantation.
\end{abstract}

Key words: haemopoietic stem cells; CAFC; long-term culture; stroma; bone marrow; cord blood; peripheral blood.

Haemopoietic stem cells (HSCs) are primitive cells that maintain blood cell production throughout an individual's lifetime. In the adult, most are located in the bone marrow and can migrate in a highly regulated fashion via the blood stream between the widely dispersed areas of haemopoietic activity.

The HSC compartment is heterogeneous in various aspects, possibly as a result of the different mitotic histories of each stem cell, caused by 
stochastic mechanisms that regulate cycling activity in a predominantly resting stem cell population (Korn et al, 1973; Nakahata et al, 1982). Analogous to the mouse, the human HSC compartment is likely to represent a hierarchy of primitive cells based on decreasing ability to generate new HSCs, decreasing pluripotentiality and proliferative potential, and increasing turnover rate (Rosendaal et al, 1979; Mauch et al, 1980; Hodgson and Bradley, 1984; Ploemacher and Brons, 1989; Ploemacher et al, 1991, 1993b; Ploemacher, 1994). For transplants, this heterogeneity may be reflected in the different time periods which individual stem cell clones contribute to long-term reconstitution of a conditioned host, irrespective of whether this includes all haemopoietic lineages (Lemischka et al, 1986; Capel et al, 1990; Harrison, 1992; Lemischka, 1992; Van der Loo et al, 1994; Ploemacher, 1994). The question then arises as to what should be denoted as a 'stem cell'. It is generally accepted that HSCs have a very low turnover rate, but considerable capability of both self-renewal and differentiation into at least eight haematolymphoid lineages.

\section{HOW DO STEM CELLS MAINTAIN THEMSELVES THROUGHOUT AN INDIVIDUAL'S LIFE?}

Many papers have been devoted to HSC 'self-maintenance' and the high expectations of 'ex vivo expansion of HSCs' and gene therapy comes from the acceptance of HSC immortality. However, there is no extensive evidence for HSC immortality and it should be questioned whether such a cell population would not endanger the integrity of life because it has qualities reminiscent of a neoplasia. Second, immortality could be interpreted in a semantic manner, so that a future potential of 50 cell divisions meets conditions of virtual self-maintenance. For example, the recent demonstration that lymphomyeloid-repopulating HSCs can expand their numbers greater than 300 -fold following their transplantation in a conditioned recipient is impressive indeed, but takes a mere eight cell divisions with full self-renewal (Pawliuk et al, 1996).

Third, a clear distinction should be made between maintenance of an individual stem cell and that of an HSC population as a whole. The wellknown cartoon of an individual stem cell that divides and produces two distinct daughter cells, one remaining 'stem cell' and the other committing itself to differentiation, may not be commonplace. Instead, operational terms should be used which apply to the whole population and characterize the HSC compartment as a cell population with a probability of selfrenewal approaching 0.5 . Alternatively, a population could be structured such that it uses a (small) number of cells as a reserve compartment, while the largest part is responsible for the daily supply of differentiated progeny. This structure can be recognized in many tissues. There is ample evidence for a metabolically quiescent HSC population with relatively low turnover that harbours a high proliferative potential and probability to give multilineage offspring. Many observations suggest that in the steady state only a few stem cell clones display clonogenic expansion at the same time and 
contribute to daily blood cell production (Lemischka et al, 1986; Snodgrass and Keller, 1987; Capel et al, 1989; Abkovitz et al, 1990; Jordan and Lemischka, 1990; Lemischka, 1992). In transplants many different clones contribute to the initial phase of haemopoietic reconstitution, but within weeks only a few remain to provide for the demand of the body for blood cells. In contrast, the work of Harrison and colleagues supports a model where HSCs function continuously (Harrison et al, 1988; Harrison, 1992). The ultimate self-renewal capacity of HSCs is unknown, but serial transplantation studies in mice and reports on chromosome telomere shortening in humans suggest that human HSC self-replication is limited to around 50 cell divisions (Vaziri et al, 1994). Extinction of individual clones feeds back into the quiescent HSC compartment and triggers proliferation of other HSCs.

\section{REGULATION OF HSC QUIESCENCE AND PROLIFERATION}

The mechanisms regulating cycle activity and facilitating undifferentiated proliferation of HSCs are not completely understood and many cytokines have recently been shown to act synergetically in inducing proliferation of candidate HSCs. These factors may have growth factor activity when used as a single factor. Their action may therefore be explained by a series of assumptions, including (a) competence acquisition, i.e. they induce $G_{0}>G_{1}$ transition in an HSC without being able to drive cells through S-phase and $\mathrm{G}_{2}$ to mitosis (Suda et al, 1983), (b) they induce or upregulate receptor expression for other cytokines that can activate HSCs, (c) they downregulate receptors for negative regulators of HSCs or (d) the downstream targets of receptor-ligand complexes, the transcription molecules, act in concert to affect molecular processes essential for regulation. Many small molecules have been proposed as HSC-specific; however, none has been confirmed. The most important inhibitors are transforming growth factor$\beta 1$ (TGF- $\beta 1$ ), tumour necrosis factor- $\alpha$ (TNF- $\alpha 1)$, interferon- $\gamma$ (IFN- $\gamma$ ) and macrophage inflammatory protein-1 $\alpha$ (MIP-1 $\alpha$ ). They are often pleiotropic factors that may have both stimulatory and inhibitory properties on different cell populations. For example, TGF- $\beta 1$ stimulates monocyte cluster formation and at the same time is the most active inhibitor at the stem cell level (Ottmann and Pelus, 1988; Hampson et al, 1989; Hatzfeld et al, 1991; Ruscetti et al, 1991; Ploemacher et al, 1993a).

Cytokines that are effective in regulation of HSC proliferation, most likely in a redundant or overlapping fashion and often in synergy, are stem cell factor (SF; a ligand for the c-kit receptor), tyrosine kinase receptor 3 ligand (Flt3-L), thrombopoietin (Tpo, a ligand for c-mpl), interleukin-6 (IL-6), IL-11, IL-3, leukaemia inhibitory factor (LIF) and granulocyte colony-stimulating factor (G-CSF). The sources of these factors vary and can be autocrine, paracrine (e.g. elaborated by stromal cells in the bone marrow environment; T-cells or monocytes) or endocrine. The above molecules certainly do not act exclusively on HSCs proper and therefore specificity requires local presentation in context with other signals, possibly 
cell-cell and cell-extracellular matrix contact mediated by cell adhesion molecules (CAM) (see Chapter 4).

In addition to soluble factors elaborated by stromal cells and HSC, there could exist other more intimate levels of regulation of HSCs. Rather than exclusively determining HSC sub-localization in the haemopoietic organs, CAM could have direct regulatory effects on HSCs. For example, an antibody against LFA-1 inhibits the generation of progenitor cells by a fraction of human HSCs in stroma-supported cultures (Gunji et al, 1992).

Perhaps the best studied CAM interaction is that of c-kit and its ligand, SF (Kodama et al, 1994). SF is a receptor on stromal cells in, for example, bone marrow, reproductive organs (Sertoli cells in testes and follicular cells in ova), skin and cerebellum, whereas c-kit is the SF receptor expressed on immature cells including HSC, spermatides, oogonia and melanocytes (Yoshinaga et al, 1991; Nishikawa et al, 1991; Hirata et al, 1993; Ogawa et al, 1993; Packer et al, 1994). Loss of SF from the stromal cell membrane leads to a pleiotropic phenotype in mice (the Steel phenotype), that includes macrocytic anaemia, decreased fertility and coat colour defects. This condition largely develops as a result of a defective stem cell migration during embryogenesis and the anaemia in adult mice cannot be normalized by infusion of the soluble receptor SF, although the soluble receptor SF acts as survival factor, growth factor and a potent synergistic activity in vitro.

From embryogenesis it has become evident that genuine cell-cell communication may be even more intimate and involve coupling of intracellular compartments of adjacent cells via gap junctions (GJ). The Connexin-43 (Cx43) type GJ can be detected immunohistologically in bone marrow and its expression increases 80 to 100 -fold in murine bone marrow during the neonatal period and shortly after cytoreductive treatment of adult mice during the period when active regeneration is beginning (Rosendaal et al, 1994). We recently reported that functional blocking of all GJ intercellular communication (GJIC) between mutual stromal cells and stromal and haemopoietic cells in long-term culture (LTC) and cobblestone area forming cell (CAFC) cultures (see later) substantially inhibited haemopoietic activity. This inhibition could be fully abrogated by restoring GJIC within the first 2 weeks of culture (Ploemacher et al, in press; Rosendaal et al, in press).

It can not be excluded that there exist systemic or endocrine signals that regulate or overrule this complex local signalling network if decisive action is required following, for example, blood loss, infection or cytoreductive therapy.

\section{MEASUREMENT OF STEM CELL ACTIVITY}

Because of their low frequencies and lack of physical characteristics HSC measurements rely on functional assays. HSCs have been defined as cells that have high proliferation potential, can self-renew and give rise to multipotential lineage development. Therefore, HSC assays commonly use these 
characteristics as an endpoint. In vivo, spleen colony formation (Till and McCulloch, 1961), animal survival, competitive repopulation (Harrison et al, 1988; Harrison 1992), retransplantation (Lemischka et al, 1986; Spangrude et al, 1995) and engraftment of mice having a congenital immune-suppression (Lapidot et al, 1992), anaemia (Boggs et al, 1982; Van der Loo et al, 1994; Ploemacher, 1994) or polymorphism in an enzyme (Down and Ploemacher, 1993) or cell surface epitope (Szilvassy et al, 1989; Pawliuk et al, 1996) have been used to detect HSCs and their descendants. In vitro, clonogenic potential (Pluznik and Sachs, 1965; Bradley and Metcalf, 1966) with particular attention for multipotential or blast-colony formation (Tsuji et al, 1991) and replating efficiency, shortterm liquid (delta) cultures (Muench and Moore, 1992; Moore and Hoskins, 1994; Petzer et al, 1996; Srour et al, 1996) and long-term progenitor cell production on stromal cells (Dexter et al, 1977; Gartner and Kaplan, 1980; Sutherland et al, 1990, 1991; Breems et al, 1994) have been employed.

The effectiveness and reliability of such assays depends on many parameters, including

- HSC seeding efficiency to a specific haemopoietic organ in vivo,

- knowledge about, and availability of, growth factor combinations required to activate the most quiescent HSCs to cycle in vitro,

- insight in what context cytokines should be presented to HSCs (e.g. bound to stromal cell surfaces or extracellular matrix molecules),

- knowledge of inhibitors that maintain quiescence of HSCs, and methods to neutralize or counteract their activities,

- the time required to activate the most quiescent HSCs and

- stochastic mechanisms operating at the HSC level that determine quiescence/cycling ratio and commitment into specific differentiation lineages.

The latter issue clearly demonstrates the limitation of HSC techniques in that HSCs may not behave according to their ascribed ability for multipotential differentiation and self-renewal capacity. As discussed by Lemischka (1992) on the basis of extensive transplantation experiments with provirus-marked HSC, analysis of a reconstituted haemopoietic system at a single point in time merely defines a grafted HSC in terms of its minimal differentiation and proliferation potential. Therefore, estimation of HSC self-renewal should be preferentially done by analysis at multiple points in time and transplantation into secondary hosts.

Finally, of concern is that human in vitro assays are difficult to validate, so assumptions have to be made on the basis of single case histories and through extrapolation of the better characterized murine and large animal models.

\section{Stem cell assays}

Various assays have been claimed to exclusively detect HSCs and even allow their enumeration. It should be realized that a genuine assay should (a) allow frequency assessment independent of the accompanying cells in 
the sample or the HSC purity, (b) be validated using in vivo endpoints and (c) permit indisputable identification of the endpoint. There is perhaps no assay that meets these requirements.

The first issue deals with the presence or absence of progenitor cells and bystander cells. For example, though properly stimulated HSCs from various sources may form colonies in semi-solid medium, such colonies would be outnumbered by progenitor-derived colonies by a factor of $5 \times 10^{2}-5 \times 10^{5}$. These figures are based on the observation of 300-500 colony-forming units in culture (CFU-C) $/ 10^{5}$ bone marrow cells (BMCs), while primitive HSCs have been reported to have a frequency of $10-20 / 10^{5}$ BMCs as estimated using LTC-IC week-5 (long term culture initiating cell) and CAFC week-6 in stroma-supported LTCs (Sutherland et al, 1990; Breems et al, 1994) or even 1/1-6 $\times 10^{6}$ using repopulation of cytokinetreated NOD/SCID (non-obese diabetes/severe combined immunodeficiency disease) mice as an endpoint (Larochelle et al, 1996; Dick, 1996). In addition, both progenitor and assessory cells elaborate cytokines and inhibitors, and consequently affect the outcome of the HSC assay.

The second requirement, one that is underrated and frankly unpopular, is that of proper assay validation. In the past 50 years it has been proposed that haemopoietic rescue from radiation-inflicted death could be induced by transfusion of body fluids, spleen homogenates, spleen or bone marrow cell suspensions, spleen colony-forming cells (CFU-S; cells that can form haemopoietic nodules in the spleen of an irradiated mouse) or long-term repopulating HSCs that have extremely low CFU-S quality. As mentioned, many types of in vitro assay methods claim to score 'stem cell quality'. Proof depends on the acceptance of a stem cell definition, and the ability to sort the target cells to high purity and show that the cells comply with the spirit of such a definition.

Third, the most relevant assays for HSC enumeration are those that have a unique endpoint, which is characteristic for HSCs, and thus discriminates HSCs from accompanying progenitors in the sample. In practice this includes all assays that detect long-term (multilineage) activity of HSCs in vivo or in vitro.

\section{Long-term cultures}

One such method is the stroma-dependent LTC of haemopoietic cells, which is routinely performed in $25 \mathrm{~cm}^{2}$ flasks (Dexter et al, 1977). LTC measures the capacity of a complement of inoculated cells to generate haemopoietic progenitor cells over a number of weeks, typically 5-8 weeks. Progenitor cells can be detected in the non-adherent cell fraction that is harvested weekly during medium changes, and in the adherent layer that can be harvested by trypsinization. The LTC thus gives an insight in the capacity of a graft to produce progenitor cells, while it remains unknown how many HSCs and progenitors contribute to it. The latter is highly relevant when differences are anticipated in the progenitor cell generating capacity of HSCs, for example, on the basis of disease, chemotherapy or following ex vivo strategies for physical or chemical purging or selection. 
In order to allow such HSC enumeration, limiting dilution type miniaturized LTC have been reported that either use CFU-C production (LTC-IC; Sutherland et al, 1990) or stroma-associated clone formation (CAFC; Ploemacher et al, 1989, 1991; Breems et al, 1994; Pettengell et al, 1994) as an endpoint for frequency calculation.

The CAFC assay is assumed to detect frequencies of the various HSC subsets with 'transient repopulating' and/or 'long-term repopulating' properties, and has been developed as an extrapolation from the murine CAFC assay (Ploemacher et al, 1989, 1991, 1993b; Ploemacher, 1994). Extensive studies using physically sorted BMC have allowed regression analysis on the applicability of the murine CAFC assay as an in vitro equivalent for a series of HSC subsets in vivo. These studies have indicated that both in vivo and in vitro early developing, short-lived clones are initiated by the transient repopulating CFU-S cells (day-12), whereas later developing and more permanent clones are descendants of more primitive long-term repopulating HSCs, that induce stable chimerism for more than a year (Ploemacher et al, 1991, 1993b; Ploemacher, 1994; Van der Loo et al, 1994). There is increasing evidence that the human CAFC assay may also detect transiently and long-term repopulating normal and leukaemic stem cell subsets (Winton and Colenda, 1987; Terpstra et al, 1996a,b; Cornelissen et al, 1997; Breems et al, 1996, 1997). Recently a good correlation was found between CAFC week-7 and cells that repopulate SCID-hu mouse bone implants 8 weeks post-engraftment, using human mobilized peripheral blood cells that were sorted on the basis of Thy-1 expression within a CD34+ (cells expressing CD34 surface marker), Lin(cells not expressing lineage-specific cell surface markers) population (Murray et al, 1995). In addition, early detectable CAFCs have the characteristics of the more differentiated and transiently repopulating HSCs (5-fluorouracil (5-FU)-sensitive, CD34 $4^{\text {mediumposilive }}$, CD38 $8^{\text {mediumhligh }}$, HLA$D^{\text {high }}$ ), whereas late CAFCs meet the phenotype routinely employed for primitive HSCs, i.e. 5-FU-resistant, CD34 high, CD38 negativernedium and HLADR $^{\text {low/dim }}$ (Breems et al, 1994; R. E. Ploemacher, unpublished observations).

Both the flask LTC and CAFC assays propagate successive clonal amplification of HSC subsets at their own expense (Fraser et al, 1990; Van der Sluijs et al, 1993). This property renders the CAFC assay useful in assessing the full haemopoietic potential of a marrow specimen in a relatively short period and in presenting a quantitative cross-section of the heterogeneous stem cell compartment.

\section{Extended long-term cultures}

Extended stroma-dependent LTC (ELTC; 8-14 weeks) have recently been described (Hao et al, 1996) which may reveal an even more primitive human HSC population than that detected in regular LTC (5 weeks) and CAFC (6-8 weeks) assays. ELTC-initiating cells (ELTC-IC) differ from LTC-IC in various respects. First, ELTC-ICs produce most CFU-C after 60 days, whereas LTC-IC do so earlier. It is not currently clear whether these differences are realistic or merely result from the use of different stromal support 
layers, cytokine combinations, sera and the monthly total replate to other stromal layers that is reported for the ELTCs. Second, in contrast to LTC-IC, which show a high level of gene marking (Larochelle et al, 1996; Hao et al, 1996), only about $1 \%$ of ELTC-ICs can be transduced. The latter characteristic is reminiscent of the low transduction efficiency of long-term repopulating cells in human clinical gene therapy trials and most large animal models (Bordignon et al, 1995; Dunbar et al, 1995; Kohn et al, 1995; Fruehauf et al, 1996; Hoogerbrugge et al, 1996). Finally, ELTC-ICs are exclusively found in the CD38- fraction of CD34+ cells, as a human SCID-repopulating cells (SRCs; Larochelle et al, 1996). In contrast, part of LTC-ICs and CAFC week 6 are $\mathrm{CD} 38^{\text {med }}$ (R.E. Ploemacher, unpublished observations).

\section{SCID mouse assay}

The propagation of human haemopoietic progenitors in mice with a severe combined immuno-deficiency syndrome has dramatically extended our insight into the repopulating abilities and frequencies of primitive human HSCs (Baum et al, 1992; Lapidot et al, 1992; Nolta et al, 1994; Vormoor et al, 1994; Larochelle et al, 1996). Grafted human HSCs proliferate in SCID mice and differentiate in the murine bone marrow to produce large numbers of LTC-ICs, CFU-Cs, immature CD34 ${ }^{\text {pos }}$ Thy $1^{\text {pos }}$ and CD $34^{\text {pos }} \mathrm{CD} 38^{\text {ncg }}$ cells, as well as mature myeloid and erythroid cells. Relatively large numbers of lymphoid cells are produced in the bone marrow, and the human engraftment of the murine thymus and spleen is almost exclusively lymphoid. Frequencies of the primitive cells that initiate the graft in sub-lethally irradiated NOD/SCID mice, the SCID-repopulating cells, are extremely low: there is about one human SRC in every $10^{6}$ umbilical cord blood (UCB) cells, one in $3 \times 10^{6}$ adult BMC and only one in $6 \times 10^{6}$ mobilized peripheral blood (PB) cells (Dick, 1996; Larochelle et al, 1996). These frequencies are far lower than estimated by the LTC-IC and CAFC assays: average CAFC week 8 numbers in all of these specimens are between 1-10 per $10^{5}$ cells. It is likely that these differences are partly due to a low seeding efficiency of the human HSC in these mice (van Henrick, unpublished data). For example, in SCID mice a 5-10-fold higher engraftment with human AML cells has been reported following pre-treatment of the recipients with macrophage-depleting $\mathrm{Cl}_{2} \mathrm{MDP}$ liposomes (Terpstra et al, 1996a). Also, the different growth requirements of these cells may affect the apparent frequencies in NOD/SCID mice. UCB cells grow spontaneously in SCID mice, but PB and BM stem cells need continuous cytokine support following their transplantation.

\section{Characterization of HSCs}

In the last four decades the description of HSC characteristics has been a reflection of methods, techniques and hardware available to investigators. HSCs emerged as typically small 'blast' cells with a relatively low buoyant density and sedimentation velocity, few and small mitochondria, a nucleus with several nucleoli and little condensed chromatin. Agreeing with these, 
they concentrate in a region of relatively low side and forward light scatter in a flow cytometer. Physical isolation studies using fluorescence-activated cell sorter (FACS) have shown that human HSCs express on their cell surface: CD34, c-kit-R, IL-6R brightly; Thy-1, CD45RA and Flt3, weakly; but not lineage-specific markers, HLA-DR, CD71, CD38 or CD33. HSCs share some of these characteristics with other cells, and therefore phenotypical identification and enumeration of HSC is still not truly feasible.

The nucleic acid dye Hoechst 33342, which hardly stains the most quiescent HSCs, has been extremely helpful in HSC isolation, as has the vital fluorochrome Rhodamine-123 (Rh123). Rh123 accumulates in mitochondria and is a substrate of the $m d r-1$ gene product, the membrane pump P-glycoprotein (Chaudhari and Roninson, 1991; Fruehauf et al, 1996), that is highly expressed in quiescent HSC. For these reasons primitive HSCs hardly stain with Rh123 (Ploemacher and Brons, 1988a,b; Craig et al, 1993; Breems et al, 1994; Leemhuis et al, 1996), but within the HSC compartment Rh123 retention increases dramatically so that the murine day-12 spleen colony forming cells are among the brightest Rh123stained cells in the bone marrow (Ploemacher and Brons, 1988a,b).

Because of their relative quiescence, primitive HSCs have been shown to be especially resistant to anti-mitotic agents (e.g. hydroxyurea, vincristine) and 5-FU (Hodgson and Bradley, 1984; Ploemacher et al, 1991; Breems et al, 1994). This property has been exploited to enrich HSCs by exclusion of all other cells (Berardi et al, 1995). In contrast, the most primitive and in vivo long-term repopulating HSCs, as well as CAFC week 5, are extremely sensitive to the alkylating agent busulphan and a number of its derivatives (Down and Ploemacher, 1993; Down et al, 1994). A long held view is that HSCs in general represent one of the most radiosensitive cell types in the body, with $a D_{\circ}$ of about $0.75 \mathrm{~Gy}$ and no sub-lethal damage (SLD) repair. This results from radiation studies carried out using the CFU-S day-7-9 assay and animal survival as endpoints. However, current views are more in line with the realization that both these methods are a measure of transient repopulating HSCs (Ploemacher and Brons, 1988a,b, Ploemacher and Brons, 1989). The recognition of heterogeneity in the HSC compartment and the development of the CAFC assay allowing the estimation of HSC subset frequencies, and thus radiation survival, has led to a more balanced appraisal of the HSC compartment radiosensitivity. It is the CFU-S day-7/CAFC day-7-10 population that shows high radiation sensitivity and lack of SLD repair (Meijne et al, 1991, 1992; Ploemacher et al, 1992), but with increasing primitivity CAFC subsets are far more radio-resistant and display high levels of SLD repair, matching or surpassing that of lung tissue (Down et al, 1995).

All of these characteristics have emerged from studies on HSC from adult donors and may, or may not, apply to HSC from other developmental stages.

\section{AREAS OF FURTHER RESEARCH}

The enrichment and in vivo expansion of HSCs using a variety of techniques and cytokine cocktails have created novel areas of applied 
research. The possible therapeutic applications for primitive HSCs are many and varied. HSCs and progenitor cells have become the vehicle of choice for administering certain genes therapeutically, including genes to treat metabolic disorders, inherited immune and haematological diseases, and acquired immune deficiency syndromes. However, although experimental data on efficient gene transfer and long-term gene expression in mice have boosted expectations for clinical application of gene therapy, the human data have been extremely disappointing. Low transduction rates of haemopoietic cells, limited lineage expression and diminishing numbers of transduced cells observed after transplantation have necessitated additional basic research (see Chapter 2).

With increasing information on the number, quality and characteristics of HSCs in UCB, this material has been efficacious as an alternative source of HSCs for transplantation in children (Broxmeyer et al, 1995). Transplants with UCB have utilized about 10-fold smaller numbers of nucleated cells than comparable transplants with BMC. However, it is believed that UCB contains a greater proportion of progenitors than BM and that their proliferative capacity as determined by colony replating, stroma-supported growth in LTC, and SCID mouse engraftment is high (Broxmeyer et al, 1992; Hows et al, 1992; Lansdorp et al, 1993; Vormoor et al, 1994; Larochelle et al, 1996). These data suggest that a single UCB collection should suffice for repopulation of the haemopoietic system of an adult. Such transplants have shown in adults long post-engraftment intervals to platelet and neutrophil recovery. Although this could have resulted from the transfusion of too few primitive HSCs, an alternative explanation could be that merely the number of transient repopulating HSC and progenitors is limited in UCB grafts. These observations therefore present a rationale for the growing number of studies wherein ex vivo 'expansion' of true HSCs and transient repopulating progenitor cells are investigated. Though impressive increases in CD34 ${ }^{+}$cells and progenitor cells have been reported, there are limited reports on net increases in the LTC-IC or CAFC week-6-8 content of cultures initiated with human BMC (Koller et al, 1993; Zandstra et al, 1994; Petzer et al, 1996; Breems et al, 1997). At the moment there is insufficient evidence that a net increase in long-term in vivo repopulating HSCs can be achieved by short-term bulk culture of a graft. In addition, we do not know how ex vivo propagation will affect the behaviour of HSCs in the recipient, including their post-transplantation homing to haemopoietic organs or ageing. Indeed, recent studies show that short in vitro incubations of both human and murine HSCs may result in significantly decreased seeding fractions and engraftment levels in conditioned (NOD/SCID) recipients (Van der Loo and Ploemacher, 1995; Larochelle et al, 1996).

Future directions may include the development of:

(a) proper HSC assays or phenotypical enumeration of HSC;

(b) large-scale strategies for separation of tumour cells from healthy HSCs in autologous grafts;

(c) methods to improve the homing of infused HSCs to the bone marrow, especially following in vitro propagation of $\mathrm{HSC}$; 
(d) alternative ways of transducing genes to HSC with high efficiency while preserving the quality of the graft;

(e) molecular methods to regulate the expression of the transduced genes;

(f) protocols that improve efficiency of HSC mobilization to the systemic circulation.

\section{SUMMARY}

The process of blood formation is sustained throughout an individual's life by a small population of HSCs. The HSC compartment represents a hierarchy of HSC subsets with decreasing proliferative ability. This heterogeneity is reflected in the varying time periods that HSCs may contribute to the initiation and maintenance of donor-type haemopoietic multilineage chimerism in vivo. The phenotype of HSC is incompletely defined rendering morphological or flow-cytometric quantitation using cell surface and intracellular markers not fully reliable. Functional HSC assays, both in vitro (CAFC, LTC-IC) and in vivo (repopulation of NOD/SCID mice) may be superior to phenotypic analysis, but such assays have not been truly validated in a human transplant setting. The quiescence and proliferation of HSCs is highly regulated by the stroma in haemopoietic organs. Many of the cytokines that have been cloned in recent years are actually elaborated and presented by the haemopoietic organ stroma cells and are supposed to serve as local regulators in order to gain specificity and avoid pleiotropic and thus undesired side-effects. Most probably, additional stroma-derived factors will be characterized, as suggested by the observation that HSCs produce more progeny in stroma-contact than in its absence or in stromaconditioned medium, irrespective of the exogenous cytokines included.

Stem cells are considered to possess the ability to self-renew and are therefore attractive vehicles for gene therapy. This assumed characteristic has fuelled attempts to amplify their numbers ex vivo, and is expected to enable more rapid haemopoietic recovery of conditioned recipients as well as enlarge HSC grafts of insufficient size before actual transplantation.

\section{REFERENCES}

*Abkovitz JL, Linenberger ML, Newton MA et al (1990) Evidence for the maintenance of hematopoiesis in a large animal by the sequential activation of stem-cell clones. Proceedings of the National Academy of Sciences of the USA 87: 9062-9066.

Baum CM, Weissman CL, Tsukamoto AS et al (1992) Isolation of a candidate human hematopoietic stem-cell population. Proceedings of the National Academy of Sciences of the USA 89: 2804-2808.

Berardi AC, Wang A, Levine JD (1995) Functional isolation and characterization of human hematopoietic stem cells. Science 267: 104-108.

Boggs DR, Bogs SS, Saxe DF et al (1982) Hematopoietic stem cells with high proliferative potential: assay of their concentration in marrow by the frequency and duration of cure of W/Wv mice. Journal of Clinical Investigations 70: 242-253.

Bordignon C, Notarangelo L, Nobili N et al (1995) Gene therapy in peripheral blood lymphocytes and bone marrow for ADA-immunodeficient patients. Science 270: 470-475. 
Bradley TR \& Metcalf D (1966) The growth of mouse bone marrow cells in vitro. Australian Journal of Experimental Biology \& Medical Science 44: 287-299.

*Breems DA, Blokland EAW, Neben S \& Ploemacher RE (1994) Frequency analysis of human primitive haematopoietic stem cell subsets using a cobblestone area forming cell assay. Leukemia 8: 1095-1104.

Breems DA, Blokland EAW \& Ploemacher RE (1997) Stroma-conditioned media improve expansion of human primitive hematopoietic stem cells and progenitors. Leukemia 11: 142-150.

* Breems DA, van Hennik PB, Kusadasi $\mathrm{N}$ et al (1996) Individual stem cell quality in leukapheresis product is related to the number of mobilized stem cells as determined using long-term culture and cobblestone area forming cell assays. Blood 87: 5370-5378.

Broxmeyer HE, Hangoc G, Cooper S et al (1992) Growth characteristics and expansion of human umbilical cord blood and estimation of its potential for transplantation in adults. Proceedings of the National Academy of Sciences of the USA 89: 4109-4113.

Broxmeyer HE, Lu L, Gaddy J et al (1995) In Levitt D \& Mertelsmann R (eds) Hematopoietic Stem Cells: Biology and Therapeutic Applications, pp 297-317. New York: Marcel Dekker.

Capel B, Hawley RG \& Mintz B (1990) Long- and short-lived murine hematopoietic stem cell clones individually identified with retroviral integration markers. Blood 75: 2267-2270.

Capel B, Hawley R, Covarrubias L et al (1989) Clonal contributions of small numbers of retrovirally marked hematopoietic stem cells engrafted in unirradiated neonatal W/Wv mice. Proceedings of the National Academy of Sciences of the USA 86: 4564-4568.

Chaudhari PM \& Roninson IB (1991) Expression and activity of P-glycoprotein, a multidrug efflux pump, in human hematopoietic stem cells. Cell 66: 748-755.

Cornelissen JJ, Wognum AW, Ploemacher RE et al (1997) Efficient long-term maintenance of chronic myeloid leukemic cobblestone area forming cells on a murine stromal cell line. Leukemia 11: 126-133.

Craig W, Kay R, Cutler R \& Lansdorp PM (1993) Expression of Thy-1 on human hematopoietic progenitor cells. Journal of Experimental Medicine 177: 1331-1342.

Dexter TM, Allen TD \& Lajhta LG (1977) Condition controlling the proliferation of haemopoietic stem cells in vitro. Journal of Cellular Physiology 91: 335-342.

Dick J (1996) Normal and leukemic human stem cells assayed in SCID mice. Seminars in Immunology 8: 197-206.

Down JD \& Ploemacher RE (1993) Transient and permanent engraftment potential of murine hemopoietic stem cell subsets: differential effects of host conditioning with gamma radiation and cytotoxic drugs. Experimental Hematology 21: 913-921.

Down JD, Boudewijn A, Dillingh JH et al (1994) Relationships between ablation of distinct haematopoietic subsets and the development of donor bone marrow engraftment following recipient pretreatment with different alkylating drugs. British Journal of Cancer 70: 611616.

Down JD, Boudewijn A, Van Os $\mathrm{R}$ et al (1995) Variations in radiation dose-survival among different bone marrow hemopoietic cell subsets following fractionated irradiation. Blood 86: 122127.

Dunbar CE, Cuttler-Fox M, O'Shaughnessy JA et al (1995) Retrovirally marked CD34-enriched peripheral blood and bone marrow cells contribute to long-term engraftment after autologous transplantation. Blood 85: 3048-3057.

Fox RM (1992) Effect of peripheral-blood progenitor cells mobilised by filgrastim (G-CSF) on platelet recovery after high-dose chemotherapy. Lancet 339: 640-644.

Fraser CC, Eaves CJ, Szilvassy SJ \& Humphries RK (1990) Expansion in vitro of retrovirally marked totipotent hematopoietic stem cells. Blood 76: 1071-1076.

Fruehauf S, Breems DA, Knaän-Shanzer S et al (1996) Frequency analysis of multidrug Resistance1 Gene transfer into human primitive hemopoietic progenitor cells using the cobblestone area forming cell assay and detection of vector-mediated P-glycoprotein expression by rhodamine123. Human Gene Therapy 7: 1219-1231.

Gartner S \& Kaplan HS (1980) Long-term culture of human bone marrow cells. Proceedings of the National Academy of Sciences of the USA 77: 4756-4759.

Gunji Y, Nakamura M, Hagiwara T et al (1992) Expression and function of adhesion molecules on human hematopoietic stem cells: CD34 $\mathrm{LFA}^{-1} 1^{-}$cells are more primitive than CD $34^{+} \mathrm{LFA} 1^{+}$cells. Blood 80: 429-436.

Hampson J, Ponting ILO, Cook N et al (1989) The effects of TGF $\beta$ on haemopoietic cells. Growth Factors 1: 193-202. 
Hao Q-L, Thiemann FT, Petersen D et al (1996) Extended long-term culture reveals a highly quiescent and primitive human hematopoietic progenitor population. Blood 88: 3306-3313.

Harrison DE (1992) Evaluating functional abilities of primitive hematopoietic stern cell populations. In Muller-Sieburg C, Torok-Storb B, Visser J \& Storb R (eds) Current Topics in Microbiology and Immunology, Vol. 177, pp 13-30. Berlin: Springer Verlag.

Harrison DE, Astle CM \& Lerner C (1988) Number and continuous proliferation pattern of transplanted primitive immunohemopoietic stem cells. Proceedings of the National Academy of Sciences of the USA 85: 822-826.

Hatzfeld J, Li M-L, Brown E et al (1991) Release of early human hematopoietic progenitors from quiescence by antisense transforming growth factor $\beta 1$ or $\mathrm{Rb}$ oligonucleotides. Journal of Experimental Medicine 174: 925-929.

Hirata T, Morii E, Morimoto M et al (1993) Stem cell factor induces outgrowth of c-kit-positive neurites and supports the survival of c-kit-positive neurons in dorsal root ganglia of mouse embryos. Development 119: 49-56.

Hodgson GS \& Bradley TR (1984) In vivo kinetic status of hematopoietic stem and progenitor cells as inferred from labeling with bromodeoxyuridine. Experimental Hematology 12: 683-687.

Hoogerbrugge PM, van Beusechem VW, Fischer A et al (1996) Bone marrow gene transfer in three patients with adenosine deaminase deficiency. Gene Therapy 3: 179-183.

Hows JM, Bradley BA, Marsh JCW et al (1992) Growth of human umbilical cord blood in long term haematopoietic cultures. Lancet 340: 73-76.

Jordan CT \& Lemischka IR (1990) Clonal and systemic analysis of long-term hematopoiesis in the mouse. Genes and Development 4: 220-232.

Kodama H, Nose M, Niida S et al (1994) Involvement of the c-kit receptor in the adhesion of hematopoietic stem cells to stromal cells. Experimental Hematology 22: 979-84.

Kohn DB, Weinber KI, Nolta JA et al (1995) Engraftment of gene-modified umbilical cord blood cells in neonates with adenosine deaminase deficiency. Nature Medicine 1: 1017-1023.

Koller MR, Emerson SG \& Palsson BO (1993) Large-scale expansion of human stem and progenitor cells from bone marrow mononuclear cells in continuous perfusion cultures. Blood 82: 378 384.

Korn AP, Henkelman RM, Ottensmayer FP \& Till JE (1973) Investigations of a stochastic model of hematopoiesis. Experimental Hematology 1: 362-375.

Lansdorp PM, Dragowska W \& Mayani H (1993) Ontogeny-related changes in proliferative potential of human hematopoietic cells. Journal of Experimental Medicine 178: 787-791.

Lapidot T, Pflumio F, Doedens $M$ et al (1992) Cytokine stimulation of multilineage hematopoiesis from immature human cells engrafted in scid mice. Science 255: 1137-1141.

*Larochelle A, Vormoor J, Hanenberg $\mathrm{H}$ et al (1996) Nature Medicine 2: 1329-1337.

Leemhuis T, Yoder MC, Grigsby S et al (1996) Isolation of primitive human bone marrow hematopoietic progenitor cells using Hoechst 33342 and Rhodamine 123. Experimental Hematology 24: 1215-1224.

*Lemischka IR (1992) What we have learned from retroviral marking of hematopoietic stem cells. In Muller-Sieburg C, Torok-Storb B, Visser J \& Storb R (eds) Current Topics in Microbiology and Immunology, Vol. 177, pp 59-71. Berlin: Springer Verlag.

Lemischka IR, Raulet DH \& Mulligan RC (1986) Developmental potential and dynamic behavior of hematopoietic stem cells. Cell 45: 917-927.

Van der Loo JCM \& Ploemacher RE (1995) Marrow and spleen seeding efficiencies of all murine hematopoietic stem cell subsets are decreased by preincubation with hematopoietic growth factors. Blood 85: 2598-2606.

Van der Loo JCM, Van den Bos C, Baert MRM et al (1994) Stable multilineage hematopoiesis chimerism in alpha-thalassemic mice induced by a bone marrow subpopulation that excludes the majority of day-12 spleen colony-forming units. Blood 83: 1769-1777.

Mauch P, Greenberger IS, Botnick $L$ et al (1980) Evidence for structured variation in self-renewal capacity within long-term bone marrow cultures. Proceedings of the National Academy of Sciences of the USA 77: 2927-2930.

Meijne EIM, Ploemacher RE, Vos O \& Huiskamp R (1992) The effects of graded doses of $1 \mathrm{MeV}$ fission neutrons or X-rays on the murine hematopoietic stroma. Radiation Research 131: 302-308.

Meijne EIM, Van der Winden-Van Groenenwegen AJM, Ploemacher RE et al (1991) The effects of $\mathrm{X}$-irradiation on hematopoietic stem cell compartments in the mouse. Experimental Hematology 19: 617-623. 
Moore MAS \& Hoskins I (1994) Ex vivo expansion of cord blood-derived stem cells and progenitors. Blood Cells 20: 468-481.

Muench MO \& Moore MA (1992) Accelerated recovery of peripheral blood cell counts in mice transplanted with in vitro cytokine-expanded hematopoietic progenitors. Experimental Hematology 20: 611-618.

Murray L, Chen B, Galy A et al (1995) Enrichment of human hematopoietic stem cell activity in the CD34+ Thy $^{+}$Lin $^{-}$subpopulation from mobilized peripheral blood. Blood 85: 368-378.

Nakahata T, Gross AF \& Ogawa M (1982) A stochastic model of the primitive hemopoietic stem cells in culture. Journal of Cellular Physiology 113: 455-458.

Nishikawa S, Kusakabe M, Yoshinaga K et al (1991) In utero manipulation of coat color formation by a monoclonal anti-c-kit antibody: two distinct waves of $c$-kit-dependency during melanocyte development. EMBO Journal 10: 2111-2118.

Nolta JA, Hanley MB \& Kohan DB (1994) Sustained human hematopoiesis in immunodeficient mice by cotransplantation of marrow stroma expressing human interleukin-3: analysis of gene transduction of long-lived progenitors. Blood 82: 3041-3051.

Ogawa M, Nishikawa, Yoshinaga Hayashi S et al (1993) Expression and function of c-kit in fetal hemopoietic progenitor cells: transition from the early c-kit-independent to the late c-kitdependent wave of hemopoiesis in the murine embryo. Development 117: 1089-1098.

Ottmann OG \& Pelus LM (1988) Differential proliferative effects of transforming growth factor- $\beta$ on human hematopoietic progenitor cells. Journal of Immunology 140: 2661-2667.

Packer AI, Hsu YC, Besmer P \& Bachvarova RF (1994) The ligand of the c-kit receptor promotes oocyte growth. Developmental Biology 161: 194-205.

Pawliuk R, Eaves C \& Humphries RK (1996) Evidence of both ontogeny and transplant doseregulated expansion of hematopoietic stem cells in vivo. Blood 88: 2852-2858.

Pettengell R, Luft T, Henschler R et al (1994) Direct comparison by limiting dilution analysis of longterm culture-initiating cells in human bone marrow, umbilical cord blood, and blood stem cells. Blood 84: 3653-3659.

Petzer AL, Zandstra PW, Piret JM \& Eaves CJ (1996) Differential cytokine effects on primitive $\left(\mathrm{CD} 34^{+} \mathrm{CD} 38^{-}\right)$human hematopoietic cells: novel responses to Flt3-ligand and thrombopoietin. Journal of Experimental Medicine 183: 2551-2558.

*Petzer AL, Hogge DE, Landsdorp PM et al (1996) Self-renewal of primitive human hematopoietic cells (long-term-culture-initiating cells) in vitro and their expansion in defined medium Proceedings of the National Academy of Sciences of the USA 93: 1470-1474.

Ploemacher RE (1994) Cobblestone area forming cell (CAFC) assay. In Freshney RI, Pragnell IB \& Freshney MG (eds) CRC Culture of Specialised Cells, Vol. 2, pp 1-21. New York: Wiley-Liss Inc.

Ploemacher RE \& Brons NHC (1988a) Cells with marrow and spleen repopulating ability and forming spleen colonies on day 16,12 , and 8 are sequentially ordered on the basis of increasing rhodamine 123 retention. Journal of Cellular Physiology 136: 531-536.

Ploemacher RE \& Brons NHC (1988b) In vivo proliferative and differential properties of murine bone marrow cells separated on the basis of rhodamine-123 retention. Experimental Hematology 16: 903-907.

Ploemacher RE \& Brons NHC (1989) Separation of CFU-S from primitive cells responsible for reconstitution of the bone marrow hemopoietic stem cell compartment following irradiation: evidence for a pre-CFU-S cell. Experimental Hematology 17: 263-266.

Ploemacher RE, Van Soest PL \& Boudewijn A (1993a) Autocrine transforming growth factor- $\beta 1$ blocks colony formation and progenitor cell generation by hemopoietic stem cells stimulated with steel factor. Stem Cells 11: 336-347.

* Ploemacher RE, Van der Loo JCM, Van Beurden CAJ \& Baert MRM (1993b). Wheat germ agglutinin affinity of murine hemopoietic stem cell subpopulations is an inverse function of their long-term repopulating ability in vitro and in vivo. Leukemia $7: 120-130$.

*Ploemacher RE, Van der Sluijs JP, Voerman JSA \& Brons NHC (1989) An in vitro limiting-dilution assay of long-term repopulating hematopoietic stem cells in the mouse. Blood 74: 27552763.

Ploemacher RE, Van Os R, Van Beurden CAJ \& Down JD (1992) Murine hemopoietic stem cells with long term engraftment and marrow repopulating ability are more resistant to gamma radiation than are spleen colony forming cells. International Journal of Radiation Biology 61: 489499.

Ploemacher RE, Van der Sluijs JP, Van Beurden CAJ et al (1991) Use of limiting dilution type long- 
term marrow cultures in frequency analysis of marrow-repopulating and spleen colony-forming hematopoietic stem cells in the mouse. Blood 78: 2527-2533.

Ploemacher RE, Mayen AEM, de Koning AE et al (in press) Gap junction intercellular communication is likely to be involved in regulation of stroma-dependent proliferation of hemopoietic stem cells. In Greenberger P \& Keating A (eds) Keystone Conference on Stroma and Megakaryopoiesis February 1996. Cambridge: Cambridge University Press.

Pluznik DH \& Sachs L (1965) The cloning of nomal 'mast' cells in tissue culture. Journal of Cellular Physiology 66: 319-324.

Rosendaal M, Hodgson GS \& Bradley TR (1979) Organization of hemopoietic stem cells: the generation-age hypothesis. Cell Tissue Kinetics 12: 17-29.

Rosendaal M, Green CR, Rahman A \& Morgan D (1994) UP-regulation of the connexin43+ gap junction network in haemopoietic tissue before the growth of stem cells. Journal of Cell Science 107: 29-37.

Rosendaal M, Mayen AEM, De Koning A et al (in press) Does transmembrane communication through gap junctions enable stem cells to overcome stromal inhibition? Leukemia (in press).

Ruscetti FW, Dubois C, Falk LA et al (1991) In vivo and in vitro effects of TGF-beta 1 on normal and neoplastic haemopoiesis. Ciba-Foundation-Symposium 157: 212-227.

Van der Sluijs JP, Van den Bos C, Baert MRM et al (1993) Loss of long-term repopulating ability in long-term bone marrow culture. Leukemia 7: 725-732.

Snodgrass R \& Keller G (1987) Clonal fluctuation within the hematopoietic system in mice reconstituted with retrovirus-infected cells. EMBO Journal 6: $3955-3960$.

*Spangrude G, Brooks DM \& Tumas DB (1995) Long-term repopulation of irradiated mice with limiting numbers of purified hematopoietic stem cells: in vivo expansion of stem cell phenotype but not function. Blood 85: 1006-1016.

Srour EF, Bregni M, Traycoff CM et al (1996) Long-term hematopoietic culture-initiating cells are more abundant in mobilized peripheral blood grafts than in bone marrow but have a more limited ex vivo expansion potential. Blood Cells, Molecules \& Diseases 22: 68-81.

Suda T, Suda J \& Ogawa M (1983) Proliferative kinetics and differentiation of murine blast cell colonies in culture: evidence for variable $G_{\circ}$ periods and constant doubling rates of early pluripotent hemopoietic progenitors. Journal of Cellular Physiology 117: 308-318.

*Sutherland HJ, Lansdorp PM, Henkelman DH et al (1990) Functional characterization of individual human hematopoietic stem cells cultured at limiting dilution on supportive marrow stromal layers. Proceedings of the National Academy of Sciences of the USA 87:3584-3588.

Sutherland HJ, Eaves CJ, Lansdorp PM et al (1991) Differential regulation of primitive human hematopoietic cells in long-term cultures maintained on genetically engineered murine stromal cells. Blood 78: $666-672$.

Szilvassy SI, Lansdorp PM, Humphries RK et al (1989) Isolation in a single step of a highly enriched murine hematopoietic stem cell population with competitive long-term repopulating ability. Blood 74: 930-939.

Terpstra W, Ploemacher RE, Prins A et al (1996a) Fluorouracil spares AML cells with long term abilities in immunodeficient mice and in stromal culture. Blood 88; 1944-1950.

Terpstra W, Prins A, Ploemacher RE et al (1996b) Long term leukemia initiating capacity of a CD34 negative subpopulation of acute myeloid leukemia. Blood 87:2187-2194.

Till JE \& McCulloch EA (1961) A direct measurement of the radiation sensitivity of normal mouse bone marrow cells. Radiation Research 14: 213-222.

Tsuji K, Zsebo KM \& Ogawa M (1991) Enhancement of murine blast cell colony formation in culture by recombinant stem cell factor (rSCF), ligand for $c$-kit. Blood 78: 1223-1229.

Vaziri H, Dragowska W, Allsopp RC et al (1994) Evidence for a mitotic clock in human hematopoietic stem cells: loss of telomeric DNA with age. Proceedings of the National Academy of Sciences of the USA 91: 9857-9860.

Vormoor J, Lapidot T, Pflumio F et al (1994) Immature human cord blood progenitors engraft and proliferate to high levels in immune-deficient SCID mice. Blood 83: 2489 2497.

Wang JCY, Doedens M \& Dick JE (1997) Primitive haemopoietic cells are enriched in cord blood compared with adult bone marrow or mobilized peripheral blood as measured by the quantitative in vivo SCID-repopulating assay. Blood 89: 3919-3924.

Winton EF \& Colenda KW (1987) Use of long-term human marrow cultures to demonstrate progenitor cell precursors in marrow treated with 4-hydroperoxycyclophosphamide. Experimental Hematology 15: 710-714. 
Yoshinaga K, Nishikawa S, Ogawa M et al (1991) Role of c-kit in mouse spermatogenesis: identification of spermatogonia as a specific site of $\mathrm{c}$-kit expression and function. Development 113: $689-699$.

Zandstra PW, Eaves CJ \& Piret JM (1994) Expansion of hematopoietic progenitor cell populations in stirred suspension bioreactors of normal human bone marrow cells. BioTechnology 12: 909-914. 